\title{
INSTITUTIONAL RESEARCH
}

\author{
Kennedy Andrew Thomas*
}

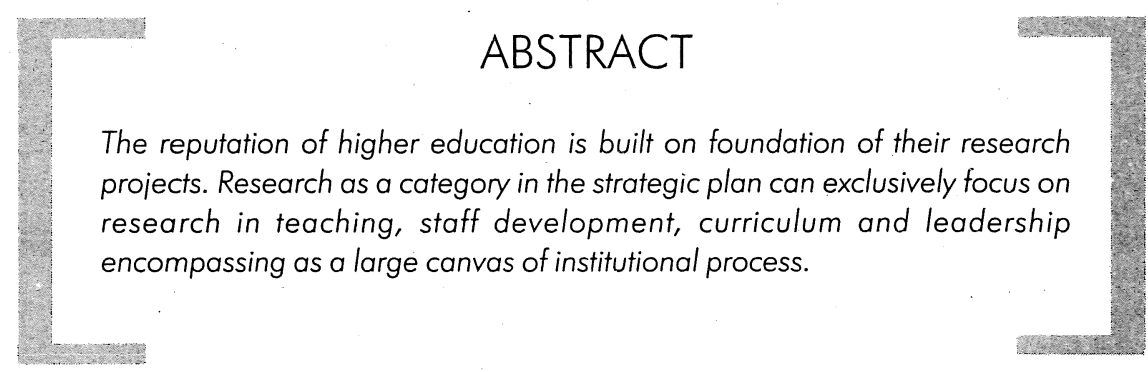

\section{Background}

The UGC leadership has been increasingly ensuring research activity in aided institutions. This is in response to wide spread criticism of the poor research record of the overwhelming majority of aided institutions. Further the commission appointed a joint secretary with a specific responsibility to fund and monitor promising research projects in colleges and universities. The reputation of institutions of higher education is built on the foundation of their research projects. Therefore the commission funds institutional individual and departmental researchers after evaluating by subject specialists. Dr. Renu Batra (May 2004) Former Assistant Professor at the Haryana Agricultural University and currently Joint Secretary, Research in the UGC).

*. Coordinator Centre for Education Beyond Curriculum (CEDBEC), Christ College, Banglore. 
Institutional Research forms another important component in Educational Management. Institutions rarely focus on researches on various dimensions that contribute to institutional effectiveness. The focus has been on subject oriented researches. Institutional effectiveness is the result of articulating and identifying the various dimensions and better its process through continuous improvement. Largely institutional effectiveness is measured by effectiveness of instruction and administration.

There are very few examples of research on different dimensions of institutional effectiveness. This refers to the initiatives undertaken by the University of Hyderabad, the University of Roourkee and the Birla Institute of Technology and Science (Stella Antony \& Gnanam A, 2003) to name a few.

The institutional critical success factors depends on the ability to improve the teaching quality, raise standards of curriculum, performance of faculty, reducing barriers to learning and enable the learner to achieve his/her potential through a research culture. Research in higher education should turn to the above factors. It is said the secret of our cultural development has been research, pushing back the areas of ignorance, by discussing new truths, which in turn, lead to better ways of doing things and better products. Research shows us the way in our difficulties. It opens new avenues and provides us to better alternatives.

Research begins with a problem. John W. Best says 'teachers will discover acres of diamonds in their own backyards and the possessor of inquisitive and imaginative mind may translate one of these problems into a worthwhile and practicable research project'. The focus of Institutional Research as discussed here cuts across the system of education such as administration and teaching, curriculum, Pedagogy and faculty development that forms an integrated whole of institutional effectiveness. Among the above components, research in teaching is of great importance.

Research in teaching encompasses, research in one's own subject area, pedagogy, curriculum and faculty development. Thus engaging in Teaching alone or both teaching and research, are responsibilities of great academic challenge. Research with this perspective attracts a faculty to aspire for a greater original contribution to the growth of knowledge and to solve problems of life.

However there is a basic differences between teaching and research. Teaching is considered secondary to research. The teaching style of the teacher engaged in research and development along side with teaching exhibits a strong element of professionalism, that is relevant to the students in the context of their challenges in professional career. 


\section{Need for Research:}

Research is both a science and an art in which attitudes, knowledge and skills develop to reexamine the ideas and static theories based on yesterday's certainties. But most of the researches confine to the analysis of some definitions already formulated by others i.e. neither they find something new nor they contribute innovative ideas. Creation of knowledge is an observable output of the educational system and this is possible only through worthwhile research.

The need for research in Higher Education arises in order to address the following

a) Urgent need in each and every field of study is not only to advance the scope of knowledge but to develop competencies to identify problems, do independent research, publish research papers and participate in academic discussions.

b) Enhance excellence of curriculum, University curriculum is loaded with heavy dosage of theory. In an effort to update the new development and practical applications, an academic should not only be a teacher, but also be capable of updating knowledge by doing research in their respective fields and beyond.

c) Improving teaching methods. The trends of delivery in Higher Education are now shifting from traditional teaching-learning models to teaching with technologies; teacher centred to learner centred and working collaboratively with others to extend and enrich learning. Scholarship of teaching is now gaining tremendous ground as an educational process. Researches in pedagogical practices must focus on the above mentioned areas.

d) External Funding for research and support exists for doctoral studies, research projects, research programmes and awards to teachers. UGC, CSIR, ICSSR, and International agencies grant research Fellowships. Research projects therefore can be generated to bring about changes that impact both institutional process and disciplines.

e) Faculty Research: Research priorities must promote internationally and nationally recognized research. The shift must be from mere M.Phil and Ph.D. studies to research projects. Basic research to development, evaluative, applied and action research.

f) Action research importantly the easiest, motivates the researcher to undertake a generic problem and to put the research findings into action. Here the researcher is interested in putting into practice the research findings into action. In this type of research diagnosis of the problem, findings and intervention 
proceeds side by side. Action research refers to the kind of research the teacher undertakes to resolve an immediate problem that has emerged out of classroom process.

g) The concept of academic community is now gaining new momentum. Research in this area should focus on how academia reflects and supports diversity of intellectual interest of students and staff. Research within the discipline and that is inter-disciplinary are important. Here the research findings should transcend into the community. Even the findings of personal Ph.D. and M.Phil studies can trickle into the academic community to form intellectual capital.

\section{Conclusion}

\section{Strategic plan}

Through strategic plan it is important that an institution reflects and organizes its high priority actions into categories such as institutional leadership, research, teaching, staff development and outreach. Research as a category in the strategic plan can exclusively focus on research in teaching, staff development, curriculum and leadership encompassing as a large canvas of institutional Processes.

\section{References}

1. Best John W \& Khan James V (1989) Research in Education, Prentice Hall of India, New Delhi.

2. Coombs, H. Phlip (1970) what is educational planning, UNESCO, Paris.

3. Glassman, A.M., Rossy, G. \& Winfield. J. (n.d.) Toward an Understanding of Higher Education Concept Publishing Company, New Delhi. University, Northridge.

4. Guralnik, D. (Ed.). (1986). Webster's New World Dictionary (2nd ed.) Cleveland, OH: Prentice Hall Press.

5. ICSSR, Research Grants (1995) India's Council of Social Science Research, New Delhi, Cambridge Press Kashmir Gate Delhi.

6. Lee Harvey and Peter T. Knight (1996) Transforming Higher Education, The society for Research into Higher Education and Open university Press, Buckingham, Great Britain and Bristol U.S.A.

7. McLean, JE (1999) Improving Education through Action Research, Corunis Press Inc., California.

8. Morrison, K (1988) Management Theories for Educational Change, Vikas Publishing House Pvt. Ltd, New Delhi.

9. National Policy on Education (1986), Ministry of Human Resources Development (Education), New Delhi. 
10. Pandya S.R. (2001) Administration and Management of Education, Himalaya Publishing House, Mumbai.

11. Power K.B. (2000) Higher Education for Human Development, Association of Indian Universities AlU, New Delhi.

12. Rowley, D.J., Lujan, H.D., \& Dolence, M.G. (1997). Strategic Change in Colleges and Universities. San Francisco, CA: Jossey-Bass Publishers.

13. Sidhu Kulbir Singh (1990) Methodology of Research in Education, Sterling Publishers, New Delhi.

14. Stella Antony \& Gnanam (2003) Foundations of External Quality Assurance in Indian Higher Education Concept Publishing Company, New Delhi.

15. Wall, S.J., S.R. (1995, Autumn). The evolution (not the death) of strategy. Organizational Dynamics. 